\title{
A Typhoon Shelter Selection and Evacuee Allocation Model: A Case Study of Macao (SAR), China
}

\author{
Xiujuan Zhao ${ }^{1,2}$, Peng Du ${ }^{2}$, Jianguo Chen ${ }^{1,2, *}$, Dapeng $\mathrm{Yu}^{3}$, Wei Xu ${ }^{4,5}$, Shiyan Lou ${ }^{6}$, \\ Hongyong Yuan ${ }^{1,2}$ and Kuai Peng Ip ${ }^{6, *}$ \\ 1 Department of Engineering Physics, Tsinghua University, Beijing 100084, China; \\ xjzhao@mail.tsinghua.edu.cn (X.Z.); hy-yuan@tsinghua.edu.cn (H.Y.) \\ 2 Institute of Public Safety Research, Tsinghua University, Beijing 100084, China; pdu@tsinghua.org.cn \\ 3 Geography and Environment, Loughborough University, Loughborough LE11 3TU, UK; D.Yu2@lboro.ac.uk \\ 4 Academy of Disaster Reduction and Emergency Management, Ministry of Emergency Management and \\ Ministry of Education, Beijing Normal University, Beijing 100875, China; xuwei@bnu.edu.cn \\ 5 Faculty of Geographical Science, Beijing Normal University, Beijing 100875, China \\ 6 Research Center for Macau Social and Economic Development, City University of Macau, \\ Macau 999078, China; sylou@cityu.mo \\ * Correspondence: chenjianguo@tsinghua.edu.cn (J.C.); kpip@cityu.mo (K.P.I.)
}

Received: 18 February 2020; Accepted: 15 April 2020; Published: 18 April 2020

\begin{abstract}
Typhoon disaster represent one of the most prominent threats to public safety in the Macao Special Administrative Region (SAR) of China and can cause severe economic losses and casualties. Prior to the landing of typhoons, affected people should be evacuated to shelters as soon as possible; this is crucial to prevent injuries and deaths. Various models aim to solve this problem, but the characteristics of disasters and evacuees are often overlooked. This study proposes a model based on the influence of a typhoon and its impact on evacuees. The model's objective is to minimize the total evacuation distance, taking into account the distance constraint. The model is solved using the spatial analysis tools of Geographic Information Systems (GIS). It is then applied in Macao to solve the evacuation process for Typhoon Mangkhut 2018. The result is an evacuee allocation plan that can help the government organize evacuation efficiently. Furthermore, the number of evacuees allocated to shelters is compared with shelter capacities, which can inform government shelter construction in the future.
\end{abstract}

Keywords: typhoon shelter; evacuee allocation; inundation depth

\section{Introduction}

One major consequence of global warming is the increased intensity and frequency of extreme weather events such as typhoons [1,2]. Constructing shelters important for disaster management, as shelters can house affected people before and during disasters. In this way, casualties can be reduced. The southeastern coastal area of China is highly vulnerable to typhoons, and the threat to people and property in this area is increasing [3]. As one of the wealthiest and most booming regions in China, the Macao Special Administrative Region (SAR) has been seriously affected by typhoon disasters (especially Typhoon Hato, in 2017, and Typhoon Mangkhut, in 2018). Therefore, constructing shelters, planning efficient evacuation and planning evacuee allocation are of great importance to the Macao SAR government.

Engineering techniques can mitigate the impacts of disasters such as earthquakes and typhoons [4]. However, in server cases, these techniques can no longer protect people. Therefore, the establishment of shelters and the allocation of evacuees to them is effective $[5,6]$. To determine shelter locations, 
many studies select among candidate shelters using mathematical models [7-10]. In relation to shelters that have been constructed by the government, planning evacuee allocation is equally important. The Voronoi diagram and the spatial analysis technology of Geographical Information Systems (GIS) are the most popular approaches to allocating affected people to shelters [11-14]. Single-objective models are widely used to generate schemes to allocate affected people. These include the P-median model, the P-center model, and the covering model [15-17]. Based on these single-objective models, many studies have proposed multi-objective models [18-21] and hierarchical models [10,22-25] for appropriately locating disaster shelters. For example, Zhao et al. [6,21,26] proposed a multi-objective model to solve the earthquake shelter location-allocation problem using a heuristic algorithm. Likewise, $\mathrm{Ng}$ et al. [5] proposed a hybrid two-level model to solve the hurricane shelter location-allocation problem; this determined the location of shelters in the upper level and the evacuation paths in the lower level. In relation to disaster types, some authors considered the process and impact of a disaster $[8,27]$. For earthquake disasters, the evacuation paths' condition will influence the evacuation process, as earthquakes cannot be predicted. Thus, Zhao et al. [10] considered damage to evacuation paths when solving an earthquake shelter location-allocation problem. Similarly, to solve an earthquake shelter selection and evacuee-allocation problem, $\mathrm{Xu}$ et al. [28] took into account the influence of building collapse to the number of evacuees. In relation to typhoon disasters, a few studies take into account the typhoon influence to solve shelter location and evacuee allocation problem. For example, Qin et al. [8] developed a shelter location and allocation model sensitive to the track of the typhoon, and considered anti-wind capacity within $33 \mathrm{kt}$ (Beaufort scale force 7).

Notwithstanding these previous achievements, there is scope for further research on the typhoon shelter allocation problem. Many researchers have set up models to solve the typhoon shelter location-allocation problem, but have overlooked characteristics of the typhoon. For example, Pan [27] and Dalal et al. [29] set up models for solving typhoon shelter location problems, but neither considered the influence of the typhoon and the flood caused. Meanwhile, although researchers such as Qin et al. [8] and Li et al. [24] considered typhoon characteristics, they only considered wind; in a city, the flood caused by a typhoon tends to affect evacuation more seriously than wind. Furthermore, for flooding, although some studies of shelter location-allocation problems considered the flooding area, they disregarded inundation depth. Thus, this paper considers both the inundation depth and area caused by a typhoon to develop a typhoon shelter allocation model. This can be used to allocate affected people to shelters constructed by the government. The model's objective is to minimize the total evacuation distance of evacuees. The typhoon's impact on buildings is considered to estimate the number of evacuees, and coastal flooding due to the typhoon is simulated using the 2D version of FloodMap [30,31]. The model is then solved with the spatial analysis tools of the GIS. Typhoon Mangkhut 2018 was one of the most serious typhoons in Macao's history, and caused widespread inundation. In this study, the proposed model is applied to solve the evacuation process for Typhoon Mangkhut 2018. The results illustrate that, under a super typhoon, the evacuee allocation plan can help the government organize and conduct evacuations efficiently. Furthermore, the number of evacuees allocated to shelters is compared with shelter capacity, to inform future shelter construction.

\section{Method}

The evacuees affected by a typhoon should be allocated to shelters. To determine how to allocate evacuees to their shelters, a mathematical model has been developed and is presented in this section. An overview of the typhoon shelter selection and evacuee allocation problem is illustrated in Figure 1.

A mathematical model, using the spatial analysis technology of GIS, enables the selection of the shelters to which evacuees from all buildings are allocated. The 2D version of Flood Map [30,31] was used to determine the affected range and the number of evacuees. Sea level and digital elevation model (DEM) data were used in 2D Flood Map to determine the inundation depth and range every fifteen minutes. The sea level data was the Macao government's observation data, from Barra Station. This provides sea level every $5 \mathrm{~min}$. The digital elevation data used for inundation modeling was provided 
by the Macao government; the resolution was $5 \mathrm{~m}$ and covered the whole city area. The inundation depth and range generated per $15 \mathrm{~min}$ using 2D Flood Map; buildings located in highly risky areas (maximum inundation depth $>1 \mathrm{~m}$ ) were then selected from all buildings in Macao.

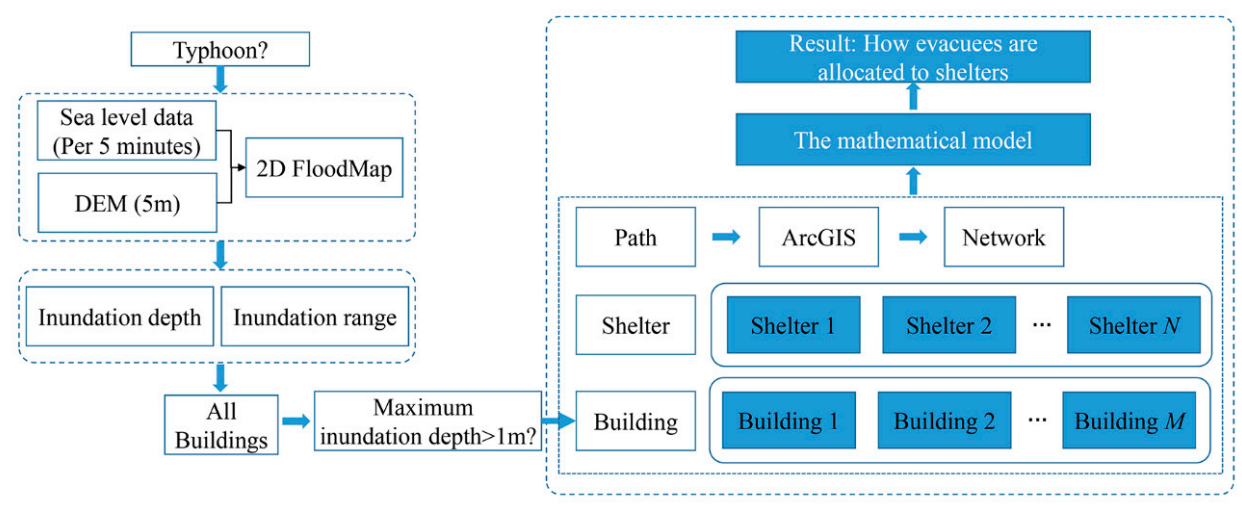

Figure 1. Method for allocating evacuees to shelters during a typhoon.

To select shelters and allocate evacuees, the first step is to establish a road network for the city. This can be done from the path data, using a network analysis tool in ArcGIS. The second dataset is the shelter layer, which lists the capacities and locations of shelters. The third dataset is the 'demand' layer, which lists both building locations and the number of evacuees per building. The mathematical model determines how evacuees are allocated to the shelters.

In the following, a mathematical model of evacuee allocation to typhoon shelter is developed. A solver model is also described, built with the GIS ModelBuilder tool to solve the mathematical model. There are three assumptions:

(1) Residents of a given building will be allocated to the same shelter;

(2) Residents will go to their assigned shelters along the shortest possible route;

(3) Residents will be allocated to shelters if the maximum inundation depths of their buildings exceed $1 \mathrm{~m}$.

\subsection{Mathematical Model for Evacuee Allocation}

The objective of the mathematical model is to minimize the total evacuation distance from all buildings, to ensure affected people reach their shelters as soon as possible.

Our notation is as follows:

$j$ : Index of building, equal to $1,2, \ldots, M$

$k$ : Index of shelter, equal to $1,2, \ldots, N$

$d_{k j}$ : Shortest evacuation route distance from building $j$ to shelter $k$

$B_{k j}$ : Whether building $j$ is assigned to shelter $k(1=$ yes, $0=$ no $)$

$D_{j}$ : The maximum evacuation distance that residents in building $j$ can travel

$X_{k}$ : Whether shelter $k$ is selected $(1=$ yes, $0=$ no)

$$
\begin{gathered}
\min f_{1}=\sum_{j=1}^{M} \sum_{k=1}^{N}\left(d_{k j} \times B_{k j}\right) \\
d_{k j} \times B_{k j}-D_{j} \leq 0 \quad \forall k=1,2, \ldots, N ; \forall j=1,2, \ldots, M \\
\sum_{k=1}^{N}\left(B_{k j} \times X_{k}\right)=1 \quad \forall j=1,2, \ldots, M
\end{gathered}
$$

Equation (1) is the objective to minimize the total evacuation distance of all affected buildings; $d_{k j}$ is the shortest distance from affected building $j$ to shelter $k$, and is calculated based on the route data. Affected buildings are defined as buildings that are inundated in the flood with a depth $>1 \mathrm{~m}$. The 
buildings' distribution and the number for each building were obtained from the Macao government. The inundation depth was calculated by modeling the coastal flooding of Typhoon Mangkhut 2018 using the 2D version of Flood Map [30,31]. As previously explained, to calculate the inundation range and depth, DEM data with resolution of $5 \mathrm{~m}$, basic geographic data, and the sea level data per five minutes were used. All data were provided by the government, with sea level data from the Barra observation station in Macao. The resolution of DEM was high and the sea level data was detailed, allowing a high-quality inundation result.

Decision variable $B_{k j}$ indicates whether the building $j$ will be allocated to shelter $k$ ( 1 allocated, 0 otherwise). Equation (2) is the distance constraint that a shelter will not be selected for a building if the distance between them is greater than $D_{j}$. This represents the furthest residents in the building can travel. Equation (3) ensures that evacuees from a given building can only be allocated to one shelter; $X_{k}$ is a decision variable that indicates whether the shelter $k$ will be selected by any building under the typhoon scenario $(1=$ selected, $0=$ not selected $)$.

\subsection{Solver Model Made by GIS Model Builder}

To solve the mathematical model, many approaches can be used, including the spatial analysis technology of GIS and optimum algorithm. The mathematical model proposed in this paper involves just one objective and the constraints are not very complex. Therefore, the ModelBuilder tool of GIS was used to solve the mathematical model. This is built based on the spatial analysis technology of GIS. The model named "shortest path" was built using the ModelBuilder tool as shown in Figure 2. Firstly, the path network was generated using GIS based on the Macao path data. Then, a network analysis tool named "make location-allocation layer" was employed, inputting the path network data. Meanwhile, shelter and building location data were provided and the model was solved. The results show which shelter will be selected by evacuees of each building for refuge.

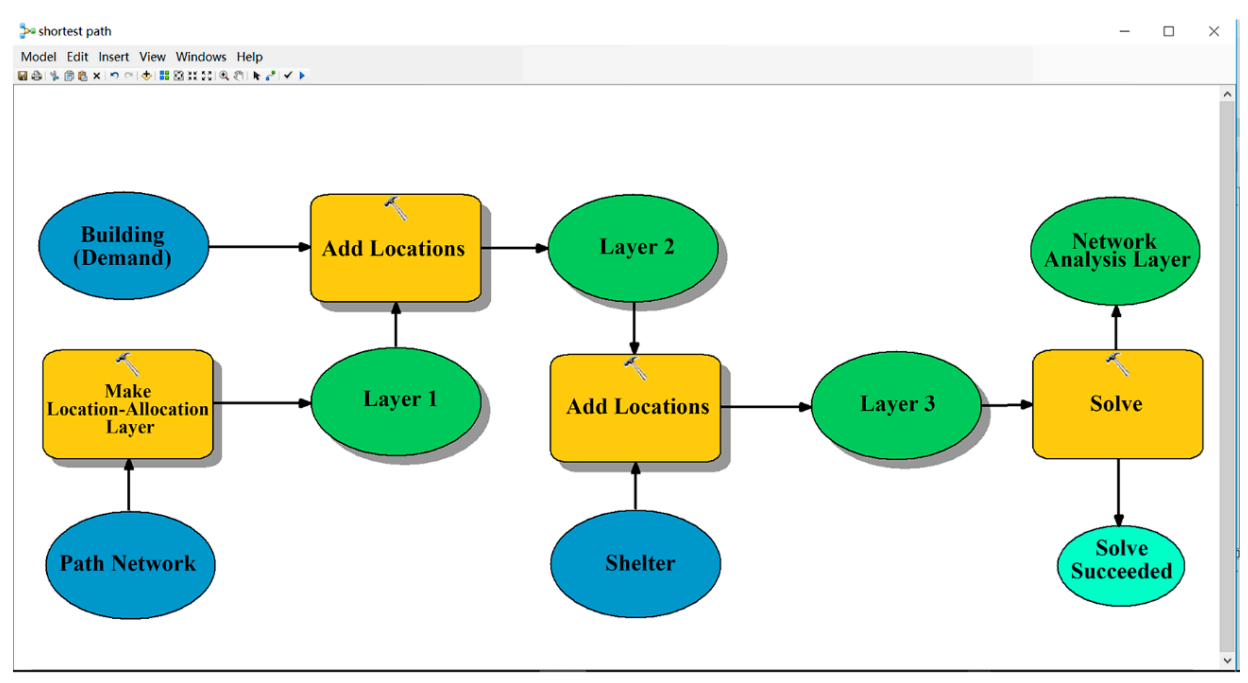

Figure 2. Solver model made by using GIS ModelBuilder.

\section{Case Study}

Macao, which is located in South China, is frequently affected by tropical cyclones. The typhoon observation record begins in 1953, but the effect of tropical cyclones on Macao was minimal until 2017, when Typhoon Hato caused the worst damage in 64 years-killing 10 injuring dozens and sweeping away 11,470 million MOP [32]. Although the government then put effort into typhoon disaster mitigation, Typhoon Mangkhut subsequently occurred in 2018, causing 40 injuries and making nearly 6000 people homeless. During typhoon disasters, most injuries and deaths are caused by inundation of houses. Therefore, providing reasonable allocation schemes for evacuees in Macao is important to avoid losses caused by typhoon disasters. 
Typhoon Mangkhut affected the entire territory of Macao. Its wind speed reached $42-48 \mathrm{~m} / \mathrm{s}$ (a magnitude of 14-15) and it caused nearly $108 \mathrm{~mm}$ of precipitation. It caused a serious storm surge, with a maximum sea level rise of $5.21 \mathrm{~m}$. The storm surge caused inundation, and the maximum inundation depth in Macao was up to $2.01 \mathrm{~m}$. During the typhoon, 598 accidents happened and were dealt with by the government. Additionally, 5650 residents was evacuated, of which 1346 lived in shelters. In this paper, Typhoon Mangkhut was selected to simulate an inundation situation and determine how to allocate evacuees to shelters.

Macao has a land area of 32.9 square kilometers; this consists of the Macao Peninsula, Taipa, and Coloane. Besides, a $1 \mathrm{~km}^{2}$ parcel of land in neighboring Hengqin island also falls under the regional government's jurisdiction. Figure 3a indicates the location of Macao in China and Figure $3 b$ illustrates its administrative divisions.
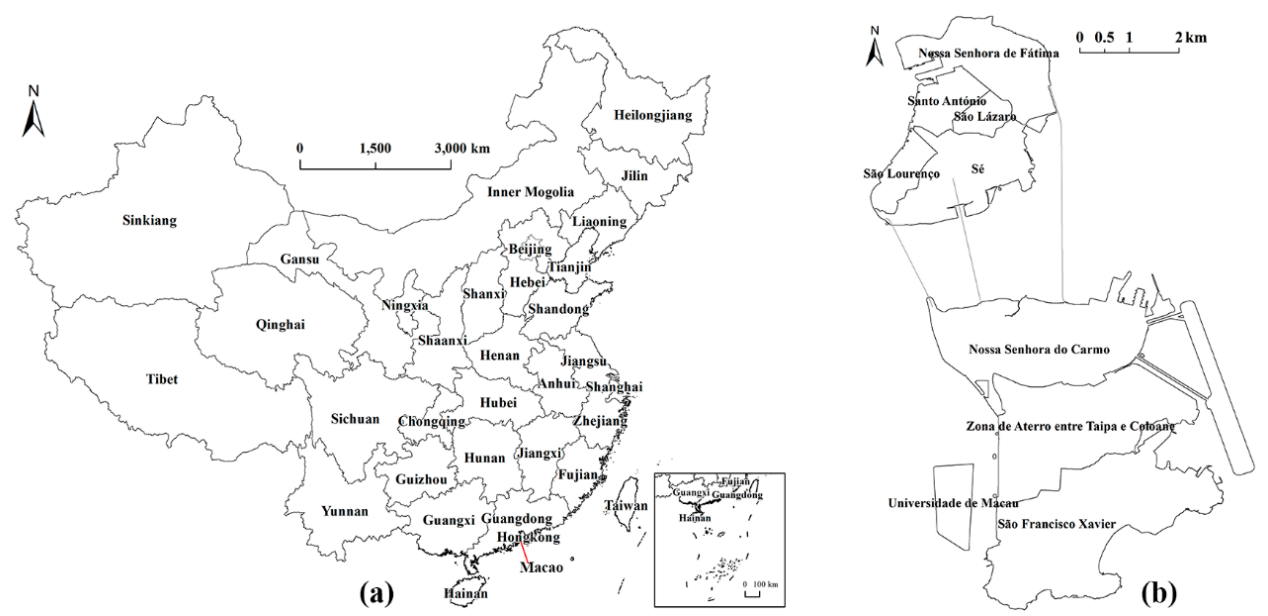

Figure 3. Location of (a) Macao in China and (b) Macao's administrative divisions.

Figure $4 \mathrm{a}, \mathrm{b}$ are maps, showing of buildings, shelters, and evacuation path network for the Macao Peninsula, Taipa and Coloane. Specifically, Figure 4a shows the locations of 11 shelters and 3716 buildings in the Macao Peninsula. Figure $4 \mathrm{~b}$ shows the locations of 6 shelters and 390 buildings in Taipa and Coloane. The sizes of shelter symbols correspond to their capacities, which are listed in Table 1 . These 17 shelters were constructed by Macao's government and are operated during typhoon disasters. The residents of the buildings need to be allocated to their designated shelters when the inundation depth is more than $1 \mathrm{~m}$. The figure shows that most of the buildings are in the Macao Peninsula, while the buildings in Taipa and Coloane are much less dense.

Table 1. Shelters and their capacities.

\begin{tabular}{ccc}
\hline ID & Name & Capacity \\
\hline 1 & Pui Ching Middle School & 794 \\
2 & Instituto Salesiano & 319 \\
3 & Colégio Mateus Ricci & 633 \\
4 & Escola Catòlica Estrela do Mar & 179 \\
5 & Tap Seac Multisport Pavilion-Pavilion B & 372 \\
6 & Multisport Pavilion, Escola Luso-Chinesa Técnico-Profissional & 1094 \\
7 & Multisport Pavilion, Polytechnic Institute & 3924 \\
8 & Ilha Verde Refuge Center & 111 \\
9 & Tap Seac Multisport Pavilion-Pavilion A & 2944 \\
10 & Keang Peng School & 169 \\
11 & Macao Federation of Trade Unions Workers Statidum & 189 \\
12 & Taipa Refugee center & 28 \\
13 & Taipa and Coloane Social Service Center & 28 \\
14 & Olympic Sports Center (Taipa) & 1883 \\
\hline
\end{tabular}


Table 1. Cont.

\begin{tabular}{ccc}
\hline ID & Name & Capacity \\
\hline 15 & Macao East Asian Games Dome (Coloane) & 10,878 \\
16 & Macao Academy of Public Security Forces & 50 \\
17 & Training Base of Macao Flying Eagle Association & 250 \\
\hline
\end{tabular}

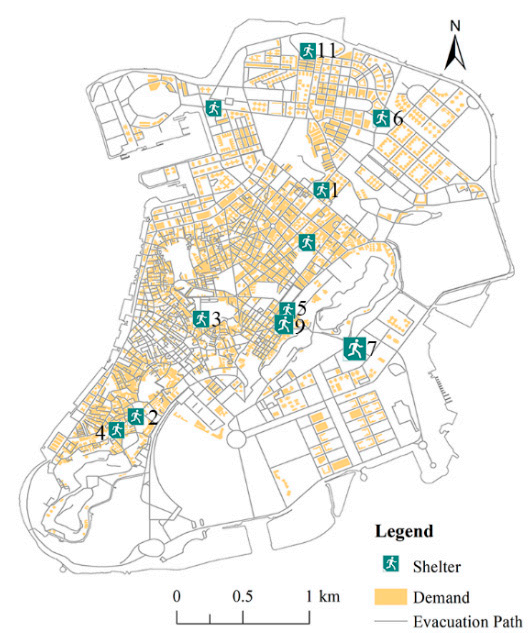

(a)

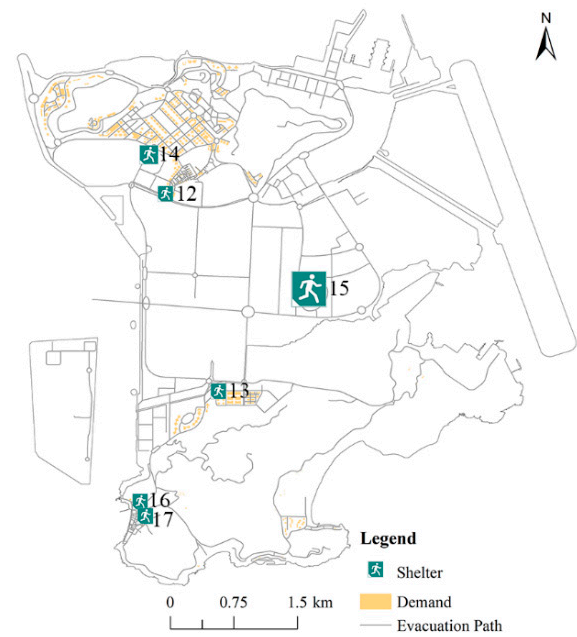

(b)

Figure 4. Location of demands, shelters, and evacuation paths in (a) the Macao Peninsula, and (b) Taipa and Coloane.

There are 11 shelters in the Macao Peninsula and 6 shelters in Taipa and Coloane. Although there are more shelters in the Macao Peninsula than in Taipa and Coloane combined, the shelters in the Macao Peninsula can house only 10,728 people in total. Meanwhile, the shelters in Taipa and Coloane can house 13,117 people in total.

\section{Results and Discussion}

In the case study area of Macao, this section shows the inundation result for Typhoon Mangkhut 2018, using a flooding estimation model. The affected buildings are determined and inputted into the mathematical model. In this way, the allocation scheme for affected buildings is generated.

\subsection{Affected Building}

The resolution of the DEM data was $5 \mathrm{~m}$, with sea level data observed by the Barra station of Macao every five minutes. This data was applied in the 2D version of Flood Map [30,31] to model the coastal flooding of Typhoon Mangkhut 2018. Compared with the sea level observation data provided by Unitary Police Service (Macao SAR.), the model could simulate the coastal flooding caused by Typhoon Mangkhut well. The coastal flooding caused by Typhoon Mangkhut was simulated, and the inundation depth per 15 min was obtained. To simplify, Figure 5; Figure 6 show the changes in inundation range and depth per four hours for the Macao Peninsula and for Taipa and Coloane. It can be seen that the inundation depth of the Macao Peninsula is deeper than that of Taipa and Coloane.

In Figure 5, the inundation depth is more than one meter in most of the Macao Peninsula, except the central area. The flooding is most serious after $4 \mathrm{~h}$. Similarly, in Figure 6, flooding in the northern part of Taipa is more visible than in the south. It can be seen that the west coast is the most affected area in Taipa and Coloane. Comparing Figures 5 and 6, it is clear that until $4 \mathrm{~h}$ after the start of the flood, the inundation depth in the west coastal area of the Macao Peninsula was more than $1 \mathrm{~m}$. Meanwhile, in the west coastal area of Taipa, it was less than one meter. 


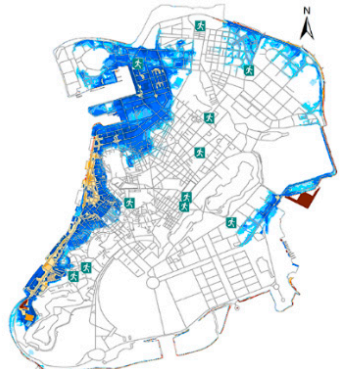

(a) $4 \mathrm{~h}$

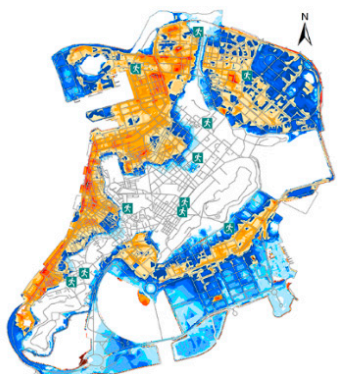

(d) $16 \mathrm{~h}$

$\square 0.00 \cdot 0.25$

$\square 0.25 \cdot 0.50$

$\square 0.50 \cdot 0.75$

$0.75 \cdot 1.00$

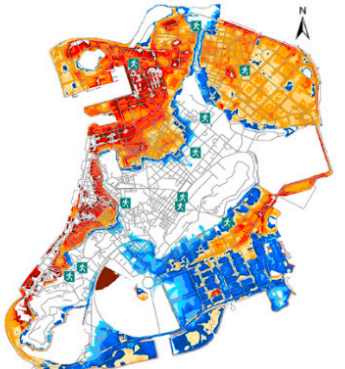

(b) $8 \mathrm{~h}$

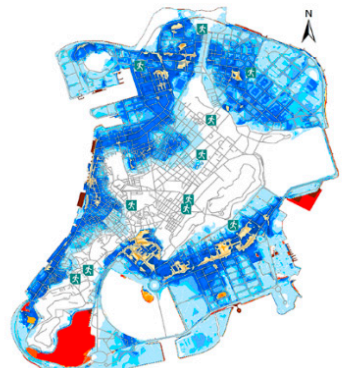

(e) $20 \mathrm{~h}$

-2.00-2.25 $=3.00$

$\square 2.25 \cdot 2.50$

$2.50 \cdot 2.75$

ㅁ. $2.75 \cdot 3.00$

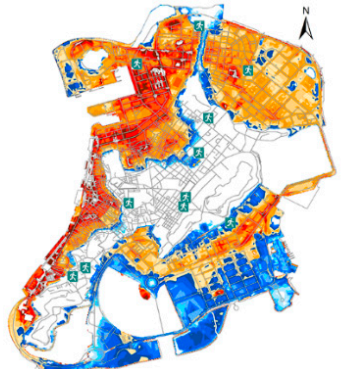

(c) $12 \mathrm{~h}$

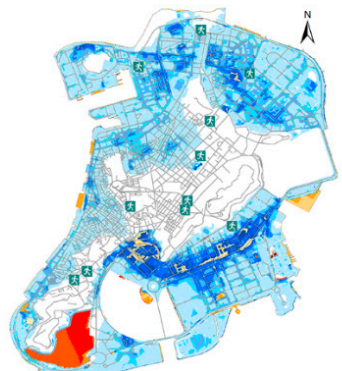

(f) $24 \mathrm{~h}$

Legend

졍 Shelter

- Evacuation Patt

Figure 5. Inundation depth per $4 \mathrm{~h}$ in the Macao Peninsula. Inundation depth is at (a) $4 \mathrm{~h}$, (b) $8 \mathrm{~h}$, (c) $12 \mathrm{~h},(\mathrm{~d}) 16 \mathrm{~h},(\mathbf{e}) 20 \mathrm{~h},(\mathbf{f}) 24 \mathrm{~h}$.

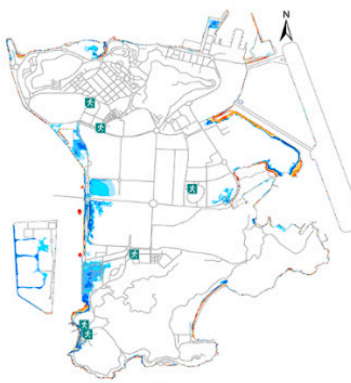

(a) $4 \mathrm{~h}$

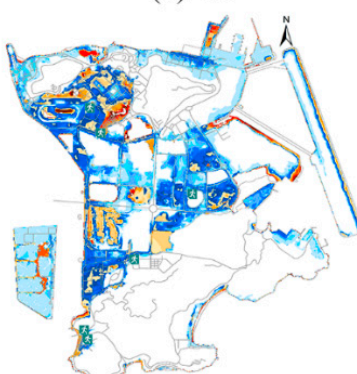

(d) $16 \mathrm{~h}$

$0.00 \cdot 0.25$

$0.50 \cdot 0.75$

$0.75 \cdot 100$

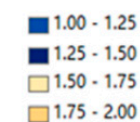

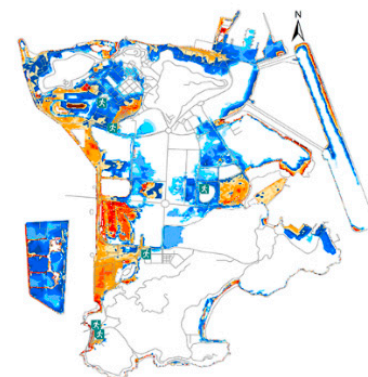

(b) $8 \mathrm{~h}$

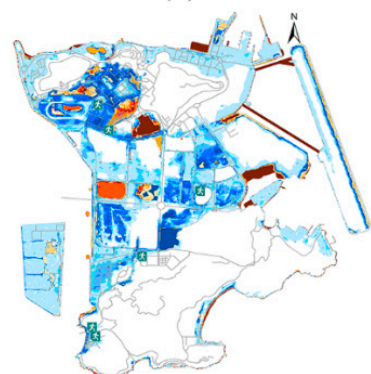

(e) $20 \mathrm{~h}$

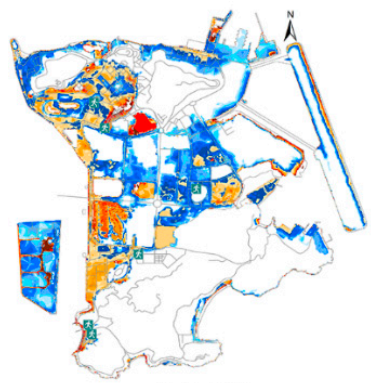

(c) $12 \mathrm{~h}$

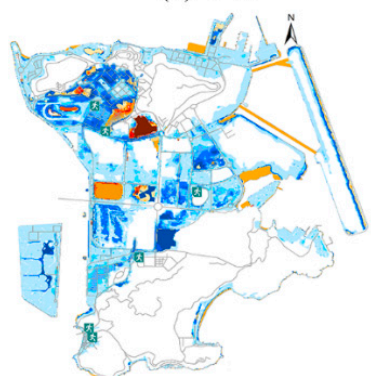

(f) $24 \mathrm{~h}$

$$
\begin{array}{r}
2.00 \cdot 2.25 \\
\square 2.25 \cdot 2.50 \\
2.50 \cdot 2.75 \\
2.75 \cdot 3.00
\end{array}
$$

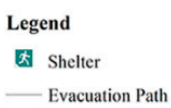

Figure 6. Inundation depth per $4 \mathrm{~h}$ in Taipa and Coloane. Inundation depth is at (a) $4 \mathrm{~h}$, (b) $8 \mathrm{~h}$, (c) $12 \mathrm{~h}$, (d) $16 \mathrm{~h},(\mathrm{e}) 20 \mathrm{~h}$, (f) $24 \mathrm{~h}$.

In this paper, it is assumed that the people in buildings where the inundation depth reaches more than one meter during the inundation process should be evacuated. Figure 7 shows the maximum inundation range where the depth reaches more than one meter. The buildings in this range were 
selected from among all of the buildings and are shown in the figure. There were a total of 2,258 buildings from which evacuation to shelters was required. Notably, Macao Peninsula was much more affected than Taipa and Coloane in terms of the number of evacuated buildings. It can also be seen that some shelters are in the area where the inundation depth is more than one meter. For these shelters, the government will make additional preparation to ensure evacuee safety. Moreover, as evacuees cannot walk on paths where the inundation depth is more than one meter, all of the evacuees should be evacuated as soon as possible upon receiving warnings, before the typhoon arrives. Compared with other typhoon location-allocation studies, the results in this paper could help the government to obtain knowledge about high risk areas and the people who need to be evacuated. Based on this information, the evacuees could be estimated.

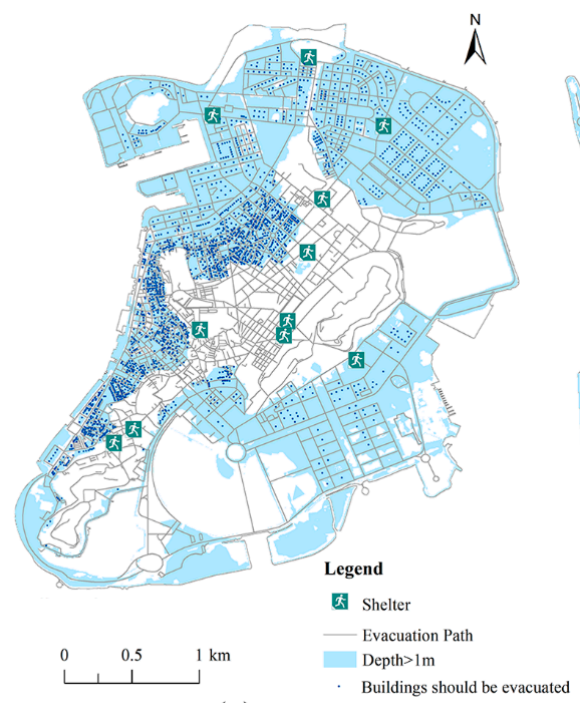

(a)

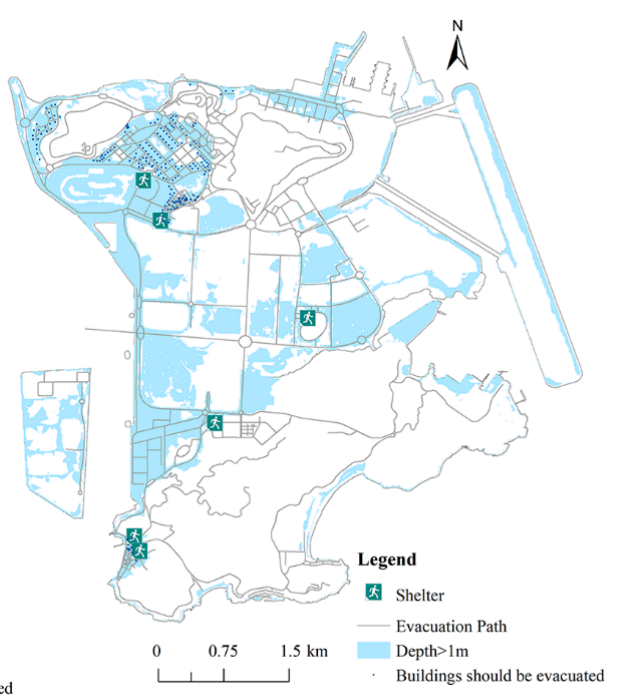

(b)

Figure 7. Inundation area where the inundation depth is more than $1 \mathrm{~m}$ in (a) the Macao Peninsula, and (b) Taipa and Coloane.

\subsection{Evacuee Allocation}

With the solution of the mathematical model obtained using GIS ModelBuilder, the scheme for typhoon shelter selection and evacuees allocation was obtained. This is shown in Figure 8. The buildings and their assigned shelters are connected with different colored lines, according to the shelters allocated. Evacuees in these buildings should be allocated to shelters, as the inundation depth is more than one meter. It can be seen that all of the shelters are selected in the Macao Peninsula, while two shelters are not selected on the offshore island (Taipa and Coloane). The two unselected shelters are Taipa and Coloane Social Service Center, and Macao East Asian Games Dome (Coloane). This does not imply that these shelters are suboptimal in terms of construction and capacity. In fact, there are many buildings (where the inundation depth is not $>1 \mathrm{~m}$ ) near shelter 13 (Taipa and Coloane Social Service Center). If these buildings are affected by inundation, the evacuees can quickly reach shelter 13 . Shelter 15 is the Macao East Asian Games Dome (Coloane), whose capacity is the greatest of all 17 shelters. Thus, these two shelters can potentially be of service when the other shelters' capacities are insufficient.

In Figure 8, it can also be observed that there are some intersecting lines. This is because of the paths' condition and paths' connectivity. For example, assume that the straight distance between building $\mathrm{A}$ and shelter $\mathrm{A}$ is greater than between building $\mathrm{A}$ and shelter $\mathrm{B}$. However, the route, which comprises different paths between building $\mathrm{A}$ and shelter $\mathrm{A}$, could be shorter than that between building A and shelter B. For the Macao Peninsula, the average evacuation distance is $573 \mathrm{~m}$, while the maximum evacuation distance is $2081 \mathrm{~m}$ and the minimum evacuation distance is $53 \mathrm{~m}$. For Taipa and Coloane, the average evacuation distance is $1139 \mathrm{~m}$, while the maximum evacuation distance is $2724 \mathrm{~m}$ and the minimum evacuation distance is $28 \mathrm{~m}$. 


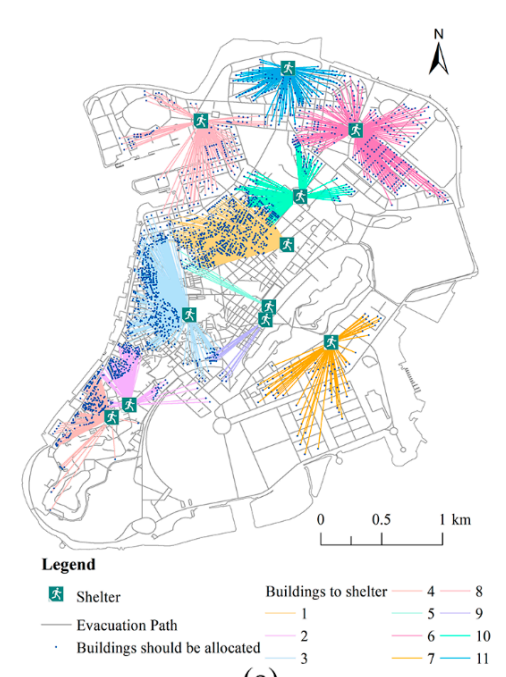

(a)

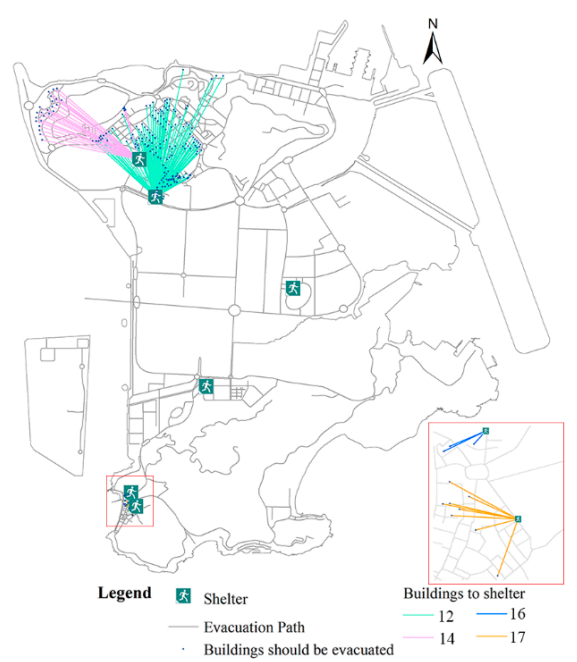

(b)

Figure 8. Scheme of typhoon shelter selection and evacuee allocation for (a) the Macao Peninsula, and

(b) Taipa and Coloane.

Table 2 presents the numbers of buildings, people, and evacuees allocated to each shelter. Notably, the number of people assumes that all of the people in the buildings go to shelters. However, typhoons are unlike other disasters, such as earthquakes. Well-built and tall buildings tend not be affected much by inundation resulting from typhoon disasters. Thus, not all of the people in buildings will go to shelters. According to the simulation results for the inundation, and experience, only residents living on the ground floor should be allocated to shelters. According to data provided by Statistics and Census Bureau, the average height of the buildings is $28 \mathrm{~m}$, which equals around 9 floors. It can thus be estimated that the population living on a building's ground floor is only around one-ninth of the total population. Table 2 indicates that only shelter 5, 7, 9, 13, 14 and 15 can accommodate the evacuees allocated. However, there are many other ways to influence evacuee's behavior, so that some people may go to other cities for a short period prior to the typhoon. Therefore, there are usually not so many people to house in the shelters. Even so, the government still needs to enhance the shelters' capacities.

Table 2. Number of buildings and people allocated to shelters.

\begin{tabular}{cccc}
\hline Shelter ID & Number of Buildings & Number of People & Number of Evacuees \\
\hline 1 & 563 & 132,206 & 14,690 \\
2 & 180 & 15,387 & 1710 \\
3 & 433 & 34,446 & 3827 \\
4 & 182 & 27,205 & 3023 \\
5 & 9 & 2516 & 280 \\
6 & 231 & 66,004 & 7334 \\
\hline 7 & 68 & 7931 & 881 \\
8 & 135 & 34,721 & 3858 \\
9 & 14 & 1338 & 149 \\
10 & 136 & 27,825 & 3092 \\
11 & 105 & 25,520 & 2836 \\
12 & 165 & 47,322 & 5258 \\
13 & 0 & 0 & 0 \\
14 & 28 & 8455 & 939 \\
15 & 0 & 0 & 0 \\
16 & 3 & 942 & 105 \\
17 & 6 & 2845 & 316 \\
\hline
\end{tabular}




\subsection{Discussion}

As mentioned, this paper considers the inundation caused by a typhoon; this has usually been overlooked in other literature. Inundation was modeled using DEM data with high resolution $(5 \mathrm{~m})$. In general, the resolution of DEM data is higher and the modeling is better, but the modeling time is longer. Overall, the $5 \mathrm{~m}$ resolution of DEM data is better for modeling inundation. Using the estimated inundation, the number of evacuees in each building was estimated. The number of evacuees allocated to each of the 17 Macao government shelters was then compared with the shelter capacities. In the case of Typhoon Mangkhut 2018, residents in buildings where inundation was less than $1 \mathrm{~m}$ did not evacuate. Additionally, residents above the ground floor were safe in their homes even if their buildings were affected, as the maximum inundation depth was $2.01 \mathrm{~m}$. Thus, the government could carry out rescue and evacuation more accurately, and emergency resources could be used in a more effective way. For Typhoon Mangkhut 2018, 11 shelters in the Macao Peninsula and 4 shelters in Taipa and Coloane were selected. The other two shelters were not selected by evacuees in this paper, as they were relatively far away from the affected buildings. However, these shelters remain important; indeed, they will be essential for accommodating surge evacuees if other shelters are full. The selected shelters would be crowded if all evacuees chose to come, especially shelter 1 . Most of the shelters' capacities are smaller than the number of evacuees allocated to them. Even though the government could help some evacuees to go to shelter 13 and 15, combined capacity of all 17 shelters is still inadequate. In this paper, the capacity constraint was not considered in the mathematical model as it has been done in other studies. These studies assumed that if a shelter could not accommodate all members of a community, it would not be selected by the community, even if it were nearer than other larger shelters. To achieve system-optimal behavior, some evacuees must go further to shelters; however, people might exhibit self-centered behavior and to go to nearer shelters overlooking the shelter's capacity. Therefore, in this paper, the capacity constraint was not considered in the mathematical model; instead, the shelters' capacities were considered after the result of the mathematical model was obtained. The number of evacuees allocated to each shelter and the capacities of each shelter are shown in Table 3. This indicates that most shelters cannot satisfy the needs of the evacuees near them, especially shelter 1.

Table 3. Shelters' capacities and the number of evacuees allocated to them.

\begin{tabular}{ccccc}
\hline ID & Capacity & Number of Evacuees Allocated to the Shelter & Unutilized Capacity & Approach \\
\hline 1 & 794 & 14,690 & $-13,896$ & Enlarge \\
2 & 319 & 1710 & -1391 & Enlarge \\
3 & 633 & 3827 & -3194 & Enlarge \\
4 & 179 & 3023 & -2844 & Enlarge \\
5 & 372 & 280 & 92 & Enough \\
6 & 1094 & 7334 & -6240 & Enlarge \\
7 & 3924 & 881 & 3043 & Enough \\
8 & 111 & 3858 & -3743 & Enlarge \\
9 & 2944 & 149 & 2795 & Enough \\
10 & 169 & 3092 & -2923 & Enlarge \\
11 & 189 & 2836 & -2647 & Enlarge \\
\hline 12 & 28 & 5258 & -5230 & Enlarge \\
13 & 28 & 0 & 28 & Enough \\
14 & 1883 & 939 & 944 & Enough \\
15 & 10,878 & 0 & 10,878 & Enough \\
16 & 50 & 105 & -55 & Enlarge \\
17 & 250 & 316 & -66 & Enlarge \\
\hline
\end{tabular}

On the other hand, the number of evacuees per building was estimated based on average building height because of the lack of other data. In reality, the ground floors of some buildings are used as stores, which was not considered in this paper. Furthermore, all of the evacuees were assumed to go to shelters. In reality, they could opt for other safe places, such as their friends' houses. Thus, the number 
of evacuees allocated to shelters obtained from the model may be greater than the true number of evacuees. However, as shown in Table 3, some shelters have a much lower capacity than the number of evacuees allocated to them. Therefore, it is suggested that the government should consider expanding existing shelters or build more shelters on suitable sites. For example, the capacities of shelter 1, 6 and 12 are much too low for the number of evacuees allocated to them, so they need to be expanded. Although the capacities of shelters 16 and 17 are also insufficient according to our results, the gaps are much smaller; therefore, they can maintain their status, as some evacuees will not choose to go to shelters. By comparing the capacity of each shelter with the number of evacuees allocated to it, the government can achieve better planning of shelter construction and improvement.

In future work, the number of evacuees can be estimated more realistically, by considering the usage of some buildings' ground floors. Moreover, surveys could help determine the number of evacuees willing to go to shelters. Another assumption was that the objective of the model was to minimize total evacuation distance rather than evacuation time. Walking speeds and the proportions of people of different ages were not considered in this paper. This factor also should be considered in future work.

\section{Conclusions}

The aim of this paper was to present work on allocating affected people to shelters constructed by the government. The number of affected people was determined using the flooding simulation model. Our findings can inform future work on affected people allocation. They can also help the government to plan the construction of new shelters and improvement of existing shelters.

In this paper, a mathematical model designed to minimize total evacuation distance was proposed, with a distance constraint. A flooding simulation model was used to simulate the inundation process caused by Typhoon Mangkhut 2018; the affected buildings from which residents should be evacuated were then identified. In the model, all of the existing shelters in the Macao peninsula were occupied, while two shelters in Taipa and Coloane were not. Moreover, considering the average building height, the number of evacuees was estimated. The results show if all affected people chose to go to shelters, the government would need to improve the capacities of the 17 existing shelters.

In further work, a number of improvements could be made. Firstly, the number of people that live in the ground floor of each building should be determined, and the number of affect people can be estimated in more detail. In this way, the capacities of shelters can be assessed to help the government improve current shelters. Additionally, the willingness of affected people to evacuate should be considered, since some people will not go to shelters even if they are affected by a typhoon. Furthermore, the influence of older people and children on the evacuation process can be analyzed. Finally, dynamic changes in road networks and buildings due to damage caused by a typhoon can be considered.

Author Contributions: Conceptualization, X.Z., P.D., and J.C.; methodology, X.Z., J.C., D.Y., and W.X.; software, X.Z., P.D., and D.Y.; validation, X.Z., J.C., S.L., and P.D.; formal analysis, X.Z. and W.X.; investigation, X.Z. and S.L.; resources, X.Z.; data curation, X.Z.; writing-original draft preparation, X.Z.; writing-review and editing, X.Z., P.D., and K.P.I.; supervision, H.Y. and J.C.; project administration, J.C. and H.Y.; funding acquisition, J.C. All authors have read and agreed to the published version of the manuscript.

Funding: This research was funded by National Natural Science Foundation of China, grant number 71861167002, Macao Science and Technology Development Fund, grant number 0049/2018/AFJ, National Natural Science Foundation of China, grant number 71790613 and Tsinghua-Foshan Innovation Special Fund (TFISF), grant number 2018THFS0301.

Acknowledgments: Thanks for Unitary Police Service (Macao S.A.R.), Public Security Forces Affairs Bureau of Macao, and Social Welfare Bureau.

Conflicts of Interest: There is no conflict of interest. 


\section{References}

1. Diffenbaugh, N.S.; Singh, D.; Mankin, J.S.; Horton, D.E.; Swain, D.L.; Touma, D.; Charland, A.; Liu, Y.; Haugen, M.; Tsiang, M.; et al. Quantifying the influence of global warming on unprecedented extreme climate events. Proc. Natl. Acad. Sci. USA 2017, 114, 4881-4886. [CrossRef] [PubMed]

2. Tsuboki, K.; Yoshioka, M.K.; Shinoda, T.; Kato, M.; Kanada, S.; Kitoh, A. Future increase of supertyphoon intensity associated with climate change. Geophys. Res. Lett. 2015, 42, 646-652. [CrossRef]

3. Mei, W.; Xie, S.P. Intensification of landfalling typhoons over the northwest Pacific since the late 1970s. Nat. Geosci. 2016, 9, 753-757. [CrossRef]

4. Chen, W.-F.; Scawthorn, C. Earthquake Engineering Handbook; CRC Press: Boca Raton, FL, USA, 2003; Volume 332, ISBN 0849309581.

5. Ng, M.W.; Park, J.; Waller, S.T. A Hybrid Bilevel Model for the Optimal Shelter Assignment in Emergency Evacuations. Comput. Civ. Infrastruct. Eng. 2010, 25, 547-556. [CrossRef]

6. Zhao, X.; Xu, W.; Ma, Y.; Hu, F. Scenario-based multi-objective optimum allocation model for earthquake emergency shelters using a modified particle swarm optimization algorithm: A case study in Chaoyang District, Beijing, China. PLoS ONE 2015, 10, 1-16. [CrossRef]

7. Bayram, V.; Tansel, B.T.; Yaman, H. Compromising system and user interests in shelter location and evacuation planning. Transp. Res. Part B Methodol. 2015, 72, 146-163. [CrossRef]

8. Qin, L.; Xu, W.; Zhao, X.; Ma, Y. Typhoon track change-based emergency shelter location-allocation model: A case study of Wenchang in Hainan province, China. Inj. Prev. 2019, 1-8. [CrossRef]

9. Sherali, H.D.; Carter, T.B.; Hobeika, A.G. A location-allocation model and algorithm for evacuation planning under hurricane/flood conditions. Transp. Res. Part B 1991, 25, 439-452. [CrossRef]

10. Zhao, X.; Coates, G.; Xu, W. A hierarchical mathematical model of the earthquake shelter location-allocation problem solved using an interleaved MPSO-GA. Geomat. Nat. Hazards Risk 2019, 10, 1712-1737. [CrossRef]

11. Li, G.; Ma, D.; Su, J. Weighted Voronoi Diagrams for Responsibility Space Regionalization of Urban Earthquake Emergency Shelters (In Chinese). Build. Sci. 2006, 22, 55-59.

12. Tai, C.a.; Lee, Y.L.; Lin, C.Y. Earthquake disaster prevention area planning considering residents' demand. In Proceedings of the 2nd International Conference on Advanced Computer Control (ICACC 2010), Shenyang, China, 27-29 March 2010.

13. Wu, W.; Zhu, S.; Zhang, W. Optimal Allocation of Emergency Shelter Facilities in Beijing (In Chinese). Hum. Geogr. 2010, 25, 41-44.

14. Zhu, P.; Zhang, J.; Xiao, H.; Tian, H. Emergency refuge function of urban green space GIS-based pattern optimization (In Chinese). J. Nat. Disasters 2010, 19, 34-42.

15. Hakimi, S.L. Optimum locations of switching centers and the absolute centers and medians of a graph. Oper. Res. 1964, 12, 450-459. [CrossRef]

16. Hakimi, S.L. Optimum Distribution of Switching Centers in a Communication Network and Some Related Graph Theoretic Problems. Oper. Res. 1965, 13, 462-475. [CrossRef]

17. Toregas, C.; Swain, R.; ReVelle, C.; Bergman, L. The Location of Emergency Service Facilities. Oper. Res. 1970, 19, 1363-1373. [CrossRef]

18. Saadatseresht, M.; Mansourian, A.; Taleai, M. Evacuation planning using multiobjective evolutionary optimization approach. Eur. J. Oper. Res. 2009, 198, 305-314. [CrossRef]

19. Barzinpour, F.; Esmaeili, V. A multi-objective relief chain location distribution model for urban disaster management. Int. J. Adv. Manuf. Technol. 2014, 70, 1291-1302. [CrossRef]

20. Rodríguez-Espíndola, O.; Gaytán, J. Scenario-based preparedness plan for floods. Nat. Hazards 2015, 76, 1241-1262. [CrossRef]

21. Xu, W.; Zhao, X.; Ma, Y.; Li, Y.; Qin, L.; Wang, Y.; Du, J. A multi-objective optimization based method for evaluating earthquake shelter location-allocation. Geomat. Nat. Hazards Risk 2018, 9, 662-677. [CrossRef]

22. Chang, M.S.; Tseng, Y.L.; Chen, J.W. A scenario planning approach for the flood emergency logistics preparation problem under uncertainty. Transp. Res. Part E Logist. Transp. Rev. 2007, 43, 737-754. [CrossRef]

23. Li, L.; Jin, M.; Zhang, L. Sheltering network planning and management with a case in the Gulf Coast region. Int. J. Prod. Econ. 2011, 131, 431-440. [CrossRef]

24. Li, A.C.Y.; Nozick, L.; Xu, N.; Davidson, R. Shelter location and transportation planning under hurricane conditions. Transp. Res. Part E Logist. Transp. Rev. 2012, 48, 715-729. [CrossRef] 
25. Widener, M.J.; Horner, M.W. A hierarchical approach to modeling hurricane disaster relief goods distribution. J. Transp. Geogr. 2011, 19, 821-828. [CrossRef]

26. Zhao, X.; Coates, G.; Xu, W. Solving the earthquake disaster shelter location-allocation problem using optimization heuristics. In Proceedings of the 14th International Conference on Information Systems for Crisis Response and Management (ISCRAM 2017), Albi, France, 21-24 May 2017.

27. Pan, A. The applications of maximal covering model in typhoon emergency shelter location problem. In Proceedings of the IEEM2010 IEEE International Conference on Industrial Engineering and Engineering Management, Macao, China, 7-10 December 2010; pp. 1727-1731.

28. Xu, W.; Ma, Y.; Zhao, X.; Li, Y.; Qin, L.; Du, J. A comparison of scenario-based hybrid bilevel and multi-objective location-allocation models for earthquake emergency shelters: A case study in the central area of Beijing, China. Int. J. Geogr. Inf. Sci. 2017, 32, 1-21. [CrossRef]

29. Dalal, J.; Mohapatra, P.K.J.; Mitra, G.C. Locating cyclone shelters: A case. Disaster Prev. Manag. 2007, 16, 235-244. [CrossRef]

30. Yu, D.; Lane, S.N. Urban fluvial flood modelling using a two-dimensional diffusion-wave treatment, part 1: Mesh resolution effects. Hydrol. Process. 2006, 20, 1541-1565. [CrossRef]

31. Yu, D.; Lane, S.N. Urban fluvial flood modelling using a two-dimensional diffusion-wave treatment, part 2: Development of a sub-grid-scale treatment. Hydrol. Process. 2006, 20, 1567-1583. [CrossRef]

32. Macao SAR government. Final Report of Typhoon Hato Assessment Summary and Suggestions on Optimizing Emergency Management System; Macao SAR Government: Macao, China, 2018.

(C) 2020 by the authors. Licensee MDPI, Basel, Switzerland. This article is an open access article distributed under the terms and conditions of the Creative Commons Attribution (CC BY) license (http://creativecommons.org/licenses/by/4.0/). 